\title{
Borderline gestational diabetes mellitus and pregnancy outcomes Hong Ju${ }^{1}$, Alice R Rumbold ${ }^{2}$, Kristyn J Willson ${ }^{3}$ and Caroline A Crowther*1
}

\begin{abstract}
Address: ${ }^{1}$ Discipline of Obstetrics and Gynaecology, The University of Adelaide, Women's and Children's Hospital, King William Road, North 5005, Australia

Email: Hong Ju - hong.ju@adelaide.edu.au; Alice R Rumbold - alice.rumbold@menzies.edu.au;

Kristyn J Willson - kristyn.willson@adelaide.edu.au; Caroline A Crowther* - caroline.crowther@adelaide.edu.au

* Corresponding author
\end{abstract} Adelaide, South Australia, 5006, Australia, ${ }^{2}$ Menzies School of Health Research \& Institute of Advanced Studies, Charles Darwin University, PO BOX 41096, Casuarina, Northern Territory, 0811, Australia and ${ }^{3}$ Discipline of Public Health, The University of Adelaide, Adelaide, South Australia,

\section{Published: 30 July 2008}

BMC Pregnancy and Childbirth 2008, 8:31 doi:10.1|86/|47|-2393-8-31

This article is available from: http://www.biomedcentral.com/|47|-2393/8/3 I

(C) 2008 Ju et al; licensee BioMed Central Ltd.

This is an Open Access article distributed under the terms of the Creative Commons Attribution License (http://creativecommons.org/licenses/by/2.0), which permits unrestricted use, distribution, and reproduction in any medium, provided the original work is properly cited.
Received: 27 February 2008

Accepted: 30 July 2008

\begin{abstract}
Background: The impact of borderline gestational diabetes mellitus (BGDM), defined as a positive oral glucose challenge test (OGCT) and normal oral glucose tolerance test (OGTT), on maternal and infant health is unclear. We assessed maternal and infant health outcomes in women with BGDM and compared these to women who had a normal OGCT screen for gestational diabetes.

Methods: We compared demographic, obstetric and neonatal outcomes between women participating in the Australian Collaborative Trial of Supplements with antioxidants Vitamin C and Vitamin E to pregnant women for the prevention of pre-eclampsia (ACTS) who had BGDM and who screened negative on OGCT.
\end{abstract}

Results: Women who had BGDM were older (mean difference I.3 years, [95\% confidence interval (CI) $0.3,2.2], p=0.0 \mathrm{I})$ and more likely to be obese $(27.1 \%$ vs $14.1 \%$, relative risk (RR) 1.92 , [95\% $\mathrm{Cl} \mathrm{I.4I,} \mathrm{2.62],} \mathrm{P}<0.000 \mathrm{I})$ than women who screened negative on OGCT. The risk of adverse maternal outcome overall was higher $(I 2.9 \%$ vs $8.1 \%$, RR I.59, $[95 \% \mathrm{Cl} I .00,2.52], \mathrm{P}=0.05)$ in women with BGDM compared with women with a normal OGCT. Women with BGDM were more likely to develop pregnancy induced hypertension (I7.9\% vs II.8\%, RR I.5I, [95\% Cl I.03, 2.20], $p=0.03$ ), have a caesarean for fetal distress (I7.I\% vs $10.5 \%$, RR I.63, [95\% Cl I.I0, $2.4 I$ ], $\mathrm{p}=0.0 \mathrm{I}$ ), and require a longer postnatal hospital stay (mean difference 0.4 day, $[95 \% \mathrm{Cl} 0 . \mathrm{I}, 0.7]$, $p=0.01)$ than those with a normal glucose tolerance.

Infants born to BGDM mothers were more likely to be born preterm (I $0.7 \%$ vs $6.4 \%, \mathrm{RR}$ I.68, [95\% $\mathrm{Cl}$ I.00, 2.80], $\mathrm{p}=0.05)$, have macrosomia (birthweight $\geq 4.5 \mathrm{~kg})(4.3 \%$ vs $1.7 \%, \mathrm{RR} 2.53,[95 \% \mathrm{Cl}$ I.06, 6.03], $\mathrm{p}=0.04)$, be admitted to the neonatal intensive care unit (NICU) $(6.5 \%$ vs $3.0 \%$, RR $2.18,[95 \% \mathrm{Cl} I .09,4.36], \mathrm{p}=0.03)$ or the neonatal nursery $(40.3 \%$ vs $28.4 \%$, RR $1.42,[95 \% \mathrm{Cl} \mathrm{I} . \mathrm{I}$, I.76], $p=0.002)$, and have a longer hospital stay $(p=0.001)$. More infants in the BGDM group had Sarnat stage 2 or 3 neonatal encephalopathy (I2.9\% vs 7.8\%, RR I.65, [95\% CI I.04, 2.63], p = 0.03).

Conclusion: Women with BGDM and their infants had an increased risk of adverse health outcomes compared with women with a negative OGCT. Intervention strategies to reduce the risks for these women and their infants need evaluation.

Trial registration: Current Controlled Trials ISRCTN004I6244 


\section{Background}

The prevalence of gestational diabetes mellitus (GDM) is increasing all over the world [1,2]. In Australia the recent prevalence estimates for GDM ranged from $5.2 \%$ to $8.8 \%$ [3]. The risks for both mothers with GDM and their infants are well-documented. For the infants, these include an increased risk of macrosomia, birth injuries such as shoulder dystocia, bone fracture and nerve palsies, hypoglycaemia, and hyperbilirubinaemia [4-7]. Women with GDM are at increased risk of developing pre-eclampsia and have an increased chance of need for induction of labour and caesarean section. Gestational diabetes is also a strong risk factor for later development of type 2 diabetes [8].

Although the risks associated with GDM are well recognised, the impact on maternal and infant health outcomes is less clear for borderline gestational diabetes mellitus (BGDM), which is characterised by values of glucose tolerance intermediate between normal and gestational diabetes. A recent 10 year audit examining the influence of different levels of glucose tolerance on pregnancy complications, [9] revealed a significantly increased risk of preeclampsia, caesarean section, neonatal hypoglycaemia and hyperbilirubinaemia for women with BGDM compared with women with normal glucose tolerance. The results are consistent with other literature reports, which identified an increasing risk of adverse maternal and infant outcomes with increasing plasma glucose values [10-12].

It is estimated that $6.6 \%$ of pregnant women or approximately 16,500 women have BGDM each year in Australia [9]. Given the uncertainty surrounding BGDM, we assessed data from participants in the Australian Collaborative Trial of Supplements with antioxidants Vitamin C and Vitamin E to pregnant women for the prevention of pre-eclampsia (ACTS) [13] to compare the maternal demographic, pregnancy and infant health outcomes of women who had BGDM (screened positive for GDM on oral glucose challenge test (OGCT) but their subsequent oral glucose tolerance test (OGTT) was normal) with women who screened negative on OGCT for GDM.

\section{Methods}

The study population included women participating in the ACTS trial [13], a multi-centre randomised placebo controlled trial of antioxidant (vitamins $\mathrm{C}$ and $\mathrm{E}$ ) supplements for the prevention of perinatal complications, who had an OGCT as screening for gestational diabetes. The methods and results of this trial have been reported previously [13]. Briefly, eligible women were: nulliparous, with a singleton pregnancy between 14 and 22 weeks of gestation with a normal blood pressure at the time of recruitment and who gave informed consent. Women with any of the following were ineligible: known multiple preg- nancy, known lethal fetal anomaly, known thrombophilia, chronic renal failure, antihypertensive therapy or contraindication to vitamin $\mathrm{C}$ or E therapy including haemochromatosis or anticoagulant therapy. Randomisation was performed through a central telephone randomisation service. Women assigned to the vitamin group were provided a daily dose of $1000 \mathrm{mg}$ vitamin $\mathrm{C}$ and $400 \mathrm{IU}$ vitamin $\mathrm{E}$ until birth, and women in the control group were provided a matching placebo. An OGTT was offered between 24-30 weeks gestation, for those women who screened positive on OGCT test. The study protocol was approved by the research and ethics committees at the nine collaboration hospitals around Australia.

We compared demographic, obstetric and neonatal outcomes between women with BGDM and those who screened normal on OGCT. As the ACTS found no significant differences between the antioxidant and placebo groups for the risk of pre-eclampsia, intrauterine growth restriction or other serious outcomes for the infant, the analyses include the combined populations of women who received either antioxidant or placebo supplements.

\section{Data collection}

Pregnancy outcome data including OGCT and OGTT results were collected prospectively from women's medical records. Sociodemographic variables were collected either from women's medical records or self-completed questionnaires at trial entry and included: maternal age, ethnicity, body mass index (BMI), social-economic status as measured by socio-economic index for area (SEIFA) score [14], maternal education, smoking status, blood pressure at trial entry, and family history of pre-eclampsia. Complete outcome data were available for all 1877 women randomised.

\section{Outcome variables}

BGDM was defined as a positive OGCT (blood glucose $\geq 7.8 \mathrm{mmol} / \mathrm{L} 1$ hour after a $50 \mathrm{~g}$ glucose load) and normal $75 \mathrm{~g}$ OGTT (fasting blood glucose $<5.5 \mathrm{mmol} / \mathrm{L}$ and 2 hour blood glucose $<7.8 \mathrm{mmol} / \mathrm{L})$. Pregnancy outcomes assessed included: maternal adverse outcomes (a composite outcome defined as any of the following until six weeks postpartum: death, pulmonary oedema, eclampsia, stroke, thrombocytopenia, renal insufficiency, respiratory arrest, placental abruption, abnormal liver function, preterm prelabour rupture of membranes, major postpartum haemorrhage, postpartum pyrexia, pneumonia, deep-vein thrombosis, or pulmonary embolus requiring anticoagulant therapy) [13]; pregnancy induced hypertension (PIH); pre-eclampsia (defined as systolic blood pressure $\geq 140 \mathrm{mmHg}$ or diastolic blood pressure [Korokoff V] $\geq 90$ $\mathrm{mmHg}$ on at least two occasions four or more hours apart, or both arising after 20 weeks' gestation and one or more of the following: proteinuria, renal insufficiency, liver dis- 
ease, neurological problems, haematologic disturbances, or fetal growth restriction) [15]; antenatal hospitalisation; preterm prelabour rupture of the membranes; induction of labour; mode of birth; postnatal complications such as postpartum haemorrhage and infection; and length of hospital stay.

Neonatal outcomes included a composite outcome of death or infant adverse outcome defined as: stillbirth or death of a liveborn infant before hospital discharge, birthweight $<3^{\text {rd }}$ centile for gestational age, severe respiratory distress syndrome, chronic lung disease, intraventricular haemorrhage grade 3 or 4, cystic periventricular leukomalacia, retinopathy of prematurity grade 3 or 4 , necrotizing enterocolitis, 5 minute Apgar score <4, seizures before 24 hours of age or requiring 2 or more drugs to control, hypotonia for $\geq 2$ hours, stupor, decreased response to pain or coma, tube feeding for $\geq 4$ days, care in the neonatal intensive care unit (NICU) $>4$ days, or use of ventilation for $\geq 24$ hours [13]; gestational age at birth; preterm birth (<37 weeks); 5 minute Apgar score $<7$, infant body size at birth (weight, length and head circumference), small and large-for-gestational age (defined as a birth weight below the $10^{\text {th }}$ percentile or above $90^{\text {th }}$ percentile for gestation according to fetal sex on standardized birth- weight charts, respectively), macrosomia (defined as birthweight $\geq 4.5 \mathrm{~kg}$ ), admission to NICU or neonatal nursery, respiratory distress syndrome, mechanical ventilation, antibiotics use after birth, encephalopathy (Sarnat 2 or 3 score) and length of hospital stay.

\section{Statistical analysis}

Statistical analysis was carried out using SAS software, version 9.1. Dichotomous variables were analysed using logbinomial regression and presented as relative risks, with 95\% confidence intervals; and continuous variables, if normally distributed, were analysed using Student's t-test and presented as mean differences, with 95\% confidence intervals; non-parametric tests were used for skewed data. Analyses were then adjusted for maternal age and BMI given the strong association of these factors with GDM. A $\mathrm{p}$ value of 0.05 or less was considered to indicate statistical significance.

\section{Results}

Of the 1877 women enrolled in the ACTS trial, 1804 (96\%) did not have a fetal loss and underwent screening using a $50 \mathrm{~g}$ oral glucose challenge test for gestational diabetes. Of the women screened 1596 (88\%) had a normal OGCT screening result, 68 (4\%) had an abnormal OGTT

Table I: Demographics of women with borderline GDM compared with women with a normal OGCT

\begin{tabular}{|c|c|c|c|c|}
\hline Characteristics & $\begin{array}{l}\text { Borderline GDM } \\
\mathrm{n}=140(\%)\end{array}$ & $\begin{array}{l}\text { Normal OGCT } \\
n=1596(\%)\end{array}$ & $\begin{array}{l}\text { Relative risk } \\
{[95 \% \mathrm{Cl}]}\end{array}$ & $\mathrm{p}$ value \\
\hline Age $^{\mathbf{a}}$ (years) & $27.5 \pm 5.4$ & $26.3 \pm 5.8$ & $1.3[0.3,2.2]$ & 0.01 \\
\hline \multicolumn{5}{|l|}{ Race } \\
\hline Caucasian & $129(92.1)$ & $1517(95.1)$ & $0.97[0.92,1.02]$ & 0.22 \\
\hline Asian & $5(3.6)$ & 47 (2.9) & $1.21[0.49,3.00]$ & 0.68 \\
\hline Other & $6(4.3)$ & $32(2.0)$ & $2.14[0.91,5.02]$ & 0.08 \\
\hline \multicolumn{5}{|l|}{ BMI } \\
\hline Underweight $(<18.5)$ & $3(2.3)$ & $59(4.0)$ & $0.59[0.19,1.80]$ & 0.34 \\
\hline Normal $(18.5-<25)$ & $59(45.7)$ & $818(55.9)$ & $0.82[0.67,0.99]$ & 0.04 \\
\hline Overweight $(25-<30)$ & $32(24.8)$ & $380(26.0)$ & $0.96[0.70,1.31]$ & 0.78 \\
\hline Obese $(\geq 30)$ & $35(27.1)$ & $207(14.1)$ & $1.92[1.41,2.62]$ & $<0.0001$ \\
\hline \multicolumn{5}{|l|}{ SEIFA' } \\
\hline Low & $40(28.6)$ & $429(26.9)$ & $1.06[0.8 \mathrm{I}, \mathrm{I} .40]$ & 0.66 \\
\hline Low-Mid & 25 (17.9) & $288(17.9)$ & $\mathrm{I} .00[0.69, \mathrm{I} .44]$ & 0.99 \\
\hline Mid-High & $37(26.4)$ & $391(24.5)$ & $1.08[0.8 \mathrm{I}, \mathrm{I} .44]$ & 0.61 \\
\hline High & $38(27.1)$ & $490(30.7)$ & $0.88[0.67,1.17]$ & 0.39 \\
\hline \multicolumn{5}{|l|}{ Education } \\
\hline Secondary or lower & $54(39.7)$ & $704(45.0)$ & $0.88[0.71,1.09]$ & 0.25 \\
\hline TAFE or equivalent & $38(27.9)$ & $361(23.1)$ & $1.21[0.91,1.61]$ & 0.19 \\
\hline University & $44(32.4)$ & $498(31.9)$ & $1.02[0.79,1.31]$ & 0.91 \\
\hline Smoking & $37(26.4)$ & $340(21.3)$ & $1.24[0.93,1.66]$ & 0.15 \\
\hline \multicolumn{5}{|l|}{ BP at trial entry $\mathbf{a}(\mathrm{mmHg})$} \\
\hline Systolic BP & $110.7 \pm 11.2$ & $110.1 \pm 10.5$ & $0.6[-1.3,2.4]$ & 0.55 \\
\hline Diastolic BP & $66.4 \pm 9.0$ & $65.3 \pm 8.0$ & I.I $[-0.3,2.5]$ & 0.12 \\
\hline
\end{tabular}

a Values are mean \pm standard deviation, and the comparisons are mean difference $(95 \% \mathrm{Cl})$

b Lower scores indicate lower socioeconomic status

BMI, Body mass index; BP, Blood pressure; SEIFA, Socio-economic index for area 
and $140(8 \%)$ had BGDM (screened positive on OGCT, normal OGTT).

Overall, women with BGDM and women with a normal OGCT had similar characteristics at entry to the study including ethnicity, socio-economic status and educational attainment (Table 1). Compared with women with a normal OGCT, women with BGDM were older (mean difference 1.3 years, [95\%CI 0.3, 2.2], $\mathrm{p}=0.01$ ), less likely to have a normal BMI (RR 0.82, [95\%CI 0.67, 0.99], $\mathrm{p}=$ 0.04 ) and almost twice as likely to be obese (RR 1.92, [95\%CI 1.41, 2.62], $\mathrm{p}<0.0001$ ) (Table 1). There was no statistically significant difference found between these groups in the number of women who smoked or in their mean systolic or diastolic blood pressure at study entry.

In unadjusted analyses women with BGDM were more likely to experience a maternal adverse outcome (RR 1.59, [95\%CI 1.00, 2.52], $\mathrm{p}=0.05$ ) and to develop pregnancy induced hypertension (RR 1.51, [95\%CI 1.03, 2.20], p = 0.03 ) compared with women with a normal OGCT. These differences were not seen when adjustment was made for maternal age and BMI. There was no significant difference in the rate of pre-eclampsia between the two comparison groups (Table 2).

The rate of induction of labour was similar and the overall caesarean section rate did not differ between groups. In the unadjusted analyses significantly more women with BGDM gave birth by caesarean section for fetal distress (RR 1.63, [95\%CI 1.10, 2.41], $\mathrm{p}=0.01$ ) compared with women with a normal OGCT although this was not significant in the adjusted analyses. The length of postnatal hospital stay was significantly longer (mean difference 0.4 days, [95\%CI 0.1, 0.7], $\mathrm{p}=0.01$ ) for women with BGDM compared to women with normal OGCT in the unadjusted analyses but not when adjusted for maternal age and BMI (Table 2).

Overall there was no difference in the risk of death or infant adverse outcome between the two groups (Table 3 ). In unadjusted analyses infants born to women with BGDM were at increased risk of being born preterm (RR $1.68,[95 \% \mathrm{CI} 1.00,2.80], \mathrm{p}=0.05)$ and were also significantly more likely to be macrosomic (birthweight $\geq 4.5 \mathrm{~kg}$ ) (RR 2.53, [95\%CI 1.06, 6.03], $\mathrm{p}=0.04$ ) compared with infants born to women with a normal OGCT. When adjusted for maternal age and BMI the association with an earlier gestational age at birth and the risk of being macrosomic remained for infants born to women with BGDM compared with infants born to women with a normal OGCT (Table 3).

The hospital stay was significantly longer (unadjusted $\mathrm{p}=$ 0.001 , adjusted $p=0.01$ ) for infants born to BGDM mothers compared with infants born to mothers with a normal

Table 2: Clinical outcomes among women with borderline GDM compared with women with a normal OGCT

\begin{tabular}{|c|c|c|c|c|c|c|}
\hline Outcome & $\begin{array}{l}\text { Borderline GDM } \\
\mathrm{n}=140(\%)\end{array}$ & $\begin{array}{l}\text { Normal OGCT } \\
n=1596(\%)\end{array}$ & $\begin{array}{l}\text { Unadjusted relative } \\
\text { risk } \\
{[95 \% \mathrm{Cl}]}\end{array}$ & p value & $\begin{array}{l}\text { Adjusted relative risk } \\
{[95 \% \mathrm{Cl}]}\end{array}$ & p value \\
\hline $\begin{array}{l}\text { Maternal adverse } \\
\text { outcome }\end{array}$ & $18(12.9)$ & $129(8.1)$ & $1.59[1.00,2.52]$ & 0.05 & $\mathrm{I} .47[0.92,2.34]$ & 0.11 \\
\hline $\begin{array}{l}\text { Pregnancy induced } \\
\text { hypertension }\end{array}$ & $25(17.9)$ & $189(11.8)$ & $1.51[1.03,2.20]$ & 0.03 & $1.31[0.90,1.90]$ & 0.16 \\
\hline Pre-eclampsia & $9(6.4)$ & $86(5.4)$ & $1.19[0.61,2.32]$ & 0.60 & $1.08[0.56 .2 .10]$ & 0.82 \\
\hline $\begin{array}{l}\text { Antenatal } \\
\text { hospitalisation }\end{array}$ & $29(20.7)$ & $287(18.0)$ & $1.15[0.82,1.62]$ & 0.42 & $1.17[0.83,1.65]$ & 0.36 \\
\hline PPROM & $6(4.3)$ & $4 \mid(2.6)$ & I.67 $[0.72,3.86]$ & 0.23 & I.54 [0.66, 3.57] & 0.32 \\
\hline Induction of labour & $49(35.0)$ & $498(31.2)$ & $1.12[0.88,1.42]$ & 0.34 & $1.06[0.84 .1 .34]$ & 0.62 \\
\hline Vaginal birth & $94(67.1)$ & $1184(74.2)$ & $0.90[0.80,1.02]$ & 0.10 & $0.96[0.86,1.08]$ & 0.48 \\
\hline Normal vaginal birth & $70(50.0)$ & $865(54.2)$ & $0.92[0.78,1.10]$ & 0.36 & $1.00[0.85 .1 .17]$ & 1.00 \\
\hline $\begin{array}{l}\text { Instrumental vaginal } \\
\text { birth }\end{array}$ & $24(17.1)$ & $319(20.0)$ & $0.86[0.59,1.25]$ & 0.42 & $0.87[0.60,1.27]$ & 0.48 \\
\hline Caesarean section & $46(32.9)$ & $412(25.8)$ & $1.27[0.99,1.64]$ & 0.06 & 1.13 [0.89. 1.43$]$ & 0.33 \\
\hline Elective & $10(7.1)$ & $101(6.3)$ & $1.13[0.60,2.11]$ & 0.70 & $\mathrm{I} .01[0.54,1.88]$ & 0.98 \\
\hline Emergency & $36(25.7)$ & $311(19.5)$ & $1.32[0.98,1.78]$ & 0.07 & I. $17[0.87,1.56]$ & 0.30 \\
\hline $\begin{array}{l}\text { Caesarean section for } \\
\text { fetal distress }\end{array}$ & $24(17.1)$ & $168(10.5)$ & $1.63[1.10,2.41]$ & 0.01 & $\mathrm{I} .43[0.97,2.1 \mathrm{I}]$ & 0.07 \\
\hline $\begin{array}{l}\text { Major postpartum } \\
\text { haemorrhage }\end{array}$ & $4(2.9)$ & $42(2.6)$ & $1.09[0.40,2.98]$ & 0.87 & $0.96[0.35,2.66]$ & 0.94 \\
\hline Postpartum pyrexia & $3(2.1)$ & $13(0.8)$ & $2.63[0.76,9.12]$ & 0.13 & $2.33[0.66,8.17]$ & 0.19 \\
\hline $\begin{array}{l}\text { Maternal length of } \\
\text { staya (days) }\end{array}$ & $3.5 \pm 2.0$ & $3.1 \pm 1.7$ & $0.4[0.1,0.7]$ & 0.01 & $0.3[-0.0 .0 .6]$ & 0.06 \\
\hline
\end{tabular}

a Value is mean \pm standard deviation, and the comparison is mean difference $(95 \% \mathrm{Cl})$. 
OGCT (Table 3). Infants born to BGDM mothers were more than twice as likely to be admitted to NICU (unadjusted $\mathrm{p}=0.03$, adjusted $\mathrm{p}=0.04$ ) and more likely to be admitted to the neonatal nursery (unadjusted $\mathrm{p}=0.002$, adjusted $\mathrm{p}=0.01$ ). Antibiotic use less than 48 hours after birth was significantly greater among infants born to BGDM mothers (unadjusted and adjusted $\mathrm{p}=0.01$ ) and more infants born to the BGDM women had Sarnat stage 2 or 3 encephalopathy (unadjusted and adjusted $\mathrm{p}=0.03$ ) compared with infants born to women with a normal OGCT (Table 3).

\section{Discussion}

In this cohort of primiparous women in Australia, 8\% were found to have BGDM. In this study, associations with BGDM were identified for maternal obesity and increasing maternal age, similar to those identified for gestational diabetes in other literature [16-18].
In our study, women with BGDM had a higher risk of adverse health outcomes overall, and were more likely to develop pregnancy induced hypertension, require a caesarean section for fetal distress and have a longer postnatal hospital stay. However, we did not detect a statistically significant increase in the risk of pre-eclampsia or caesarean section overall among women with BGDM, which has been reported by previous studies [9-11]. Increasing maternal age and BMI are strongly associated with adverse maternal health outcomes. When these factors were adjusted for, no differences were seen for health outcomes between women with BGDM and normal women.

We identified an increased risk of preterm birth amongst BGDM mothers. The reason for this is not readily apparent, given that there is no difference in the rate of induction of labour between the two groups. Infants of BGDM mothers were more likely to require a NICU and/or nurs-

Table 3: Clinical outcomes among babies born to women with borderline GDM compared with women with a normal OGCT

\begin{tabular}{|c|c|c|c|c|c|c|}
\hline Outcome & Borderline GDM & Normal OGCT & $\begin{array}{l}\text { Unadjusted relative } \\
\text { risk } \\
{[95 \% \mathrm{Cl}]}\end{array}$ & p value & $\begin{array}{l}\text { Adjusted relative risk } \\
{[95 \% \mathrm{Cl}]}\end{array}$ & P value \\
\hline Births & $\mathrm{n}=140(\%)$ & $\mathrm{n}=1596(\%)$ & & & & \\
\hline $\begin{array}{l}\text { Infant death or adverse } \\
\text { outcome }\end{array}$ & $18(12.9)$ & $162(10.2)$ & $1.27[0.80,2.00]$ & 0.31 & $1.25[0.79 .1 .98]$ & 0.34 \\
\hline Stillbirth & $\mathrm{I}(0.7)$ & $13(0.8)$ & $0.88[0.12,6.65]$ & 0.90 & $0.79[0.10,6.08]$ & 0.82 \\
\hline Neonatal death & 0 & $5(0.3)$ & -- & -- & -- & -- \\
\hline Perinatal death & $\mathrm{I}(0.7)$ & $18(1.1)$ & $0.63[0.09,4.7 I]$ & 0.66 & $0.56[0.07,4.21]$ & 0.57 \\
\hline GA at birth ${ }^{\mathrm{a}}$ (weeks) & $39.7(38.5-40.9)$ & $40.1(39.0-41.0)$ & -- & 0.004 & -- & 0.003 \\
\hline $\begin{array}{l}\text { Preterm birth } \\
\text { (GA <37 weeks) }\end{array}$ & $15(10.7)$ & $102(6.4)$ & $1.68[1.00,2.80]$ & 0.05 & $\mathrm{I} .64[0.97,2.75]$ & 0.06 \\
\hline $\begin{array}{l}\text { Very preterm birth } \\
\text { (GA <34 weeks) }\end{array}$ & $4(2.9)$ & $33(2.1)$ & $1.38[0.50,3.84]$ & 0.54 & $\mathrm{I} .40[0.50,3.91]$ & 0.53 \\
\hline $\begin{array}{l}\text { Extremely preterm } \\
\text { birth (GA <28 weeks) }\end{array}$ & 0 & $12(0.8)$ & -- & -- & -- & -- \\
\hline Apgar 5 minute $<7$ & $3(2.1)$ & $33(2.1)$ & $\mathrm{I} .04[0.32,3.33]$ & 0.95 & $\mathrm{I} .05[0.32,3.40]$ & 0.94 \\
\hline Birthweight ${ }^{\mathrm{b}}(\mathrm{g})$ & $3375 \pm 626.3$ & $3388 \pm 593.4$ & $-13.0[-116,89.5]$ & 0.80 & $-28.8[-132,73.9]$ & 0.58 \\
\hline Birth length ${ }^{\mathrm{b}}(\mathrm{cm})$ & $50.2 \pm 2.5$ & $50.3 \pm 3.3$ & $-0.06[-0.6,0.5]$ & 0.82 & $-0.09[-0.7,0.5]$ & 0.75 \\
\hline $\begin{array}{l}\text { Birth head } \\
\text { circumference }^{b}(\mathrm{~cm})\end{array}$ & $34.3 \pm 1.8$ & $34.4 \pm 1.9$ & $-0.10[-0.4,0.2]$ & 0.55 & $-0.17[-0.5,0.2]$ & 0.34 \\
\hline Liveborns & $\mathrm{n}=139(\%)$ & $\mathrm{n}=1583(\%)$ & & & & \\
\hline $\begin{array}{l}\text { SFGA (Birthweight }<10^{\text {th }} \\
\text { percentile) }\end{array}$ & $10(7.2)$ & $153(9.7)$ & $0.74[0.40,1.38]$ & 0.35 & $0.76[0.41 .1 .42]$ & 0.39 \\
\hline $\begin{array}{l}\text { LFGA (Birthweight } \geq 90^{\text {th }} \\
\text { percentile) }\end{array}$ & $19(13.7)$ & $153(9.7)$ & $1.41[0.91,2.20]$ & 0.13 & $1.29[0.83,2.00]$ & 0.27 \\
\hline $\begin{array}{l}\text { Macrosomia (Birthweight } \\
\geq 4.5 \mathrm{~kg} \text { ) }\end{array}$ & $6(4.3)$ & $27(1.7)$ & $2.53[1.06,6.03]$ & 0.04 & $2.27[0.97,5.34]$ & 0.06 \\
\hline Length of stay (days) & $3(3-5)$ & $3(2-4)$ & -- & 0.001 & -- & 0.01 \\
\hline Admission to nursery & $56(40.3)$ & $450(28.4)$ & $1.42[1.14,1.76]$ & 0.002 & $1.35[1.09,1.68]$ & 0.01 \\
\hline Admission to NICU & $9(6.5)$ & $47(3.0)$ & $2.18[1.09,4.36]$ & 0.03 & $2.05[1.02,4.13]$ & 0.04 \\
\hline RDS & 0 & $14(0.9)$ & -- & -- & -- & -- \\
\hline Mechanical ventilation & $2(1.4)$ & $33(2.1)$ & $0.69[0.17,2.85]$ & 0.61 & $0.65[0.16,2.7 I]$ & 0.56 \\
\hline Antibiotics $<48$ hours & $14(10.1)$ & $78(4.9)$ & $2.04[1.19,3.51]$ & 0.01 & $2.14[1.24,3.68]$ & 0.01 \\
\hline $\begin{array}{l}\text { Sarnat stage } 2 \text { or } 3 \\
\text { encephalopathy }\end{array}$ & $18(12.9)$ & $124(7.8)$ & $1.65[1.04,2.63]$ & 0.03 & $1.69[1.06,2.69]$ & 0.03 \\
\hline
\end{tabular}

a Values are median (IR range). b Value is mean \pm standard deviation, and the comparison is mean difference ( $95 \% \mathrm{Cl})$. GA, gestational age; SFGA, small for gestational age; LFGA, large for gestational age; NICU, neonatal intensive care unit; RDS, respiratory distress syndrome 
ery admission and longer hospital stays. This may be explained by the higher rate of pregnancy induced hypertension, caesarean section for fetal distress, preterm birth and encephalopathy (Sarnat stage 2 or 3 ) in this group. Infants born to BGDM mothers in both unadjusted analyses and when adjusted for maternal age and maternal BMI were also at higher risk of macrosomia, which is consistent with previous studies $[10,11]$.

Our study has identified increased risks of maternal adverse health outcomes overall and a range of infant adverse health outcomes associated with BGDM. In Australia, there are over 250,000 births annually [19]. Our data suggest that a substantial number of Australian pregnant women, over 20,000 each year, will have BGDM and therefore maternal and infant adverse health outcomes that are directly or indirectly attributable to BGDM. Evidence from the Australian Carbohydrate Study in Pregnant Women (ACHOIS) trial [20] confirmed that untreated mild GDM is associated with relatively rare but nonetheless significant adverse perinatal outcomes. The trial demonstrated that the risk of these outcomes can be reduced with standard treatment consisting of individual dietary and lifestyle advice during pregnancy. There is, however, insufficient evidence regarding the benefits and harms of similar intervention for women with BGDM, with only one small clinical trial identifying a significantly reduced risk of large-for-gestational age infants with dietary advice and regular blood glucose monitoring for women with borderline glucose intolerance [21]. Data from our analysis highlight the need for well-designed large randomised clinical trials to investigate the benefits and harms of such treatment for women with BGDM.

\section{Competing interests}

The authors declare that they have no competing interests.

\section{Authors' contributions}

All authors contributed to the study design, interpretation of the data and preparation of the drafts of the manuscript. In addition CAC and ARR coordinated the study and the collection of data. KJW performed the data analyses. All authors read and approved the final manuscript.

\section{Acknowledgements}

We are indebted to the women and their children who participated in the ACTS study, the ACTS Study Group [13], Helena Oakey for statistical support and Melissa Ewens for administration in support for this paper.

The ACTS trial was funded by grants from the National Health and Medical Research Council, Australia and the Channel 7 Research Foundation, South Australia.

Ethics

Children, Youth and Women's Health Service (CYWHS) Human Research and Ethics Committee (HREC)

\section{References}

I. Dabelea D, Snell-Bergeon JK, Hartsfield CL, Bischoff KJ, Hamman RF, McDuffie RS: Increasing prevalence of gestational diabetes mellitus (GDM) over time and by birth cohort: Kaiser Permanente of Colorado GDM Screening Program. Diabetes Care 2005, 28(3):579-84.

2. ACOG Committee on Practice Bulletins-Obstetrics: ACOG Practice Bulletin. Clinical management guidelines for obstetricians-gynecologists. Number 55, September 2004 (replaces practice pattern number 6, October 1997). Management of Postterm Pregnancy. Obstet Gynecol 2004, I 04(3):639-646.

3. Cheung NW, Byth K: The population health significance of gestational diabetes. Diabetes Care 2003, 26:2005-9.

4. Acker DB, Sachs BP, Friedman EA: Risk factors for shoulder dystocia. Obstet Gynecol 1985, 66(6):762-8.

5. Langer O, Yogev $Y$, Most $O$, Xenakis EM: Gestational diabetes: the consequences of not treating. Am J Obstet Gynecol 2005, 192:989-997.

6. Langer O, Rodriguez DA, Xenakis EM, McFarland MB, Berkus MD Arrendondo $\mathrm{F}$ : Intensified versus conventional management of gestational diabetes. Am J Obstet Gynecol 1994, I 70:1036-1047.

7. Soler N, Soler S, Malins ]: Neonatal morbidity among infants of diabetic mothers. Diabetes Care 1978, I:340.

8. Kim C, Newton KM, Knopp RH: Gestational diabetes and the incidence of type 2 diabetes: a systematic review. Diabetes Care 2002, 25: 1862-68.

9. Dodd JM, Crowther CA, Antoniou G, Baghurst P, Robinson JS: Screening for gestational diabetes: the effect of varying blood glucose definitions in the prediction of adverse maternal and infant health outcomes. Aust N Z J Obstet Gynaecol 2007, 47(4):307-312

10. Sermer M, Naylor CD, Gare DJ, Kenshole AB, Ritchie JW, Farine D, Cohen HR, McArthur K, Holzapfel S, Biringer A, et al:: Impact of increasing carbohydrate intolerance on maternal-fetal outcomes in 3637 women without gestational diabetes. The Toronto Tri-Hospital Gestational Diabetes Project. Am J Obstet Gynecol 1995, I 73(I): I46-I56.

II. Sermer M, Naylor CD, Farine D, Kenshole AB, Ritchie IW, Gare DJ, Cohen HR, McArthur K, Holzapfel S, Biringer A: The Toronto TriHospital Gestational Diabetes Project: A preliminary review. Diabetes Care 1998, 2 I (Suppl 2):B33-42.

12. Yogev $\mathrm{Y}, \mathrm{Xenakis} \mathrm{EM,} \mathrm{Langer} \mathrm{O}$ : The association between preeclampsia and the severity of gestational diabetes: the impact of glycemic control. Am J Obstet Gynecol 2004, I 9 I(5): I 655- I 660.

13. Rumbold AR, Crowther CA, Haslam RR, Dekker GA, Robinson JS: Vitamin $C$ and $E$ and the risks of preeclampsia and perinatal complications. New England Journal of Medicine 2006, 354(I 7): I 796-806.

14. ABS: Census of Population and Housing: Socio-economic Indexes for Areas (SEFIA). In Cat. no. 2033.0.55.00I Canberra: ABS; 200I.

I5. Brown MA, Hague WM, Higgins J, Lowe S, McCowan L, Oats J, Peek MJ, Rowan JA, Walters BN, Austalasian Society of the Study of Hypertension in Pregnancy: The detection, investigation and management of hypertension in pregnancy: full consensus statement. Aust N Z J Obstet Gynaecol 2000, 40: I39-I55.

16. Innes KE, Byers TE, Marshall JA, Baron A, Orleans M, Hamman RF: Association of a woman's own weight with subsequent risk of gestational diabetes. Journal of the American Medical Association 2002, 287:2534-4I.

17. Pettitt DJ, Bennett PH, Knowler WC, Baird HR, Aleck KA: Gestational diabetes mellitus and impaired glucose tolerance during pregnancy. Long-term effects on obesity and glucose tolerance in the offspring. Diabetes 1985, 34 Suppl 2:I 19-122.

18. Robson S, Chan A, Keane RJ, Luke CG: Subsequent birth outcomes after an unexplained stillbirth: preliminary population-based retrospective cohort study. Aust N Z J Obstet Gynaecol 2001, 41:29-35.

19. Laws PJ, Abeywardana S, Walker J, Sullivan EA: Australia's mothers and babies 2005. Perinatal statistics series no. 20. Cat. No. PER 40 2007 [http://www.npsu.unsw.edu.au/NPSUweb.nsf/page/ps20]. Sydney: AlHW National Perinatal Statistics Unit

20. Crowther CA, Hiller JE, Moss JR, McPhee AJ, Jeffries WS, Robinson JS: Australian Carbohydrate Intolerance Study in Pregnant Women (ACHOIS) Trial Group. Effect of treatment of ges- 
tational diabetes mellitus on pregnancy outcomes. New England Journal of Medicine 2005, 352:2477-86.

21. Bonomo M, Corica D, Mion E, Goncalves D, Motta G, Merati R, Ragusa A, Morabito A: Evaluating the therapeutic approach in pregnancies complicated by borderline glucose intolerance: a randomized clinical trial. Diabetic Medicine 2005, 22:|536-4I.

\section{Pre-publication history}

The pre-publication history for this paper can be accessed here:

http://www.biomedcentral.com/1471-2393/8/31/prepub

Publish with Bio Med Central and every scientist can read your work free of charge

"BioMed Central will be the most significant development for disseminating the results of biomedical research in our lifetime. "

Sir Paul Nurse, Cancer Research UK

Your research papers will be:

- available free of charge to the entire biomedical community

- peer reviewed and published immediately upon acceptance

- cited in PubMed and archived on PubMed Central

- yours - you keep the copyright

Submit your manuscript here:

http://www.biomedcentral.com/info/publishing_adv.asp 